\title{
Prevalence of Chronic Venous Diseases in Students of Ivano-Frankivsk National Medical University
}

\author{
Rostyslav Sabadosh, Mykola Ryziuk, Nazarii Ryziuk
}

\begin{abstract}
The Objective of the Research was to increase the frequency of detecting chronic venous disorders in young people by surveing the students using a specially designed questionnaire with an analysis of its results for timely treatment.

Materials and Methods. To detect lower extremity chronic venous disorders, 1, 007 students of the IvanoFrankivsk National Medical University were interviewed using questionnaire that was based on the VEIN-TERM, the Venous Clinical Severity Score, the Chronic Venous Insufficiency Quality of Life Questionnaire. In the surveyed people, there were estimated the following data: age; gender; objective symptoms of chronic venous disorders such as telangiectasia, reticular (spider) veins, varicose veins and leg swelling; 11 most common symptoms of chronic venous disorders; risk factors such as the presence of lower extremity varicose veins in parents, previous childbirth and frequent or rare use of high heels in females.

Results. In 617 (61.3\%; $95 \mathrm{Cl}, 58.2$ - 64.3\%) respondents, phlebopathy was detected; $63(6.3 \%, 95 \mathrm{Cl} 4.8$ $7.9 \%)$ students reported lower extremity telangiectasias; 11 (1.1\%; $95 \mathrm{Cl} 0.5-1.9 \%)$ students reported reticular veins. Varicose veins were detected in $33(3.3 \%$; $95 \mathrm{Cl} 2.3-4.6 \%)$ cases. Among them, there were $14(1.4 \%, 95$ $\mathrm{Cl} 0.8-2.3 \%)$ cases of leg swelling. Only two symptoms, namely calf cramps ( $p=0.01)$ and leg pain $(p=0.04)$ turned out to occur significantly more frequent in the respondents with varicose veins. Varicose veins were more often found in the students whose fathers suffered from varicose veins as compared to those whose mothers had varicose veins $-12.1 \%(95 \% \mathrm{Cl} 5.4-22.5 \%)$ versus $4.2 \%(95 \% \mathrm{Cl} 2.1-7.5 \%)$, respectively $(\mathrm{p}=0.008)$. Among females without lower extremity varicose veins, 34.1\% (95\% Cl $29.7-38.3 \%)$ of the respondents indicated wearing high heels (above $5 \mathrm{~cm}$ ) which was approximately 3 times more often as compared to female respondents with varicose veins $-11.2 \%(95 \% \mathrm{Cl} 0.0-21.7 \%)$ of women $(p=0.001)$.

Conclusions. 1. Leg pain and calf cramps can be considered as the most important subjective symptoms for early diagnosis of lower extremity varicose veins in young people. 2 . The presence of lower extremity varicose veins in a father results in higher risk of detecting this pathology in the respondent than the presence of lower extremity varicose veins in a mother: $12.1 \%(95 \% \mathrm{Cl} 5.4-22.5 \%)$ versus $4.2 \%(95 \% \mathrm{Cl} 2.1-7.5 \%)(\mathrm{p}=0.008) .3$. Early diagnostics of lower extremity varicose veins in young people with the aim of further adequate treatment to prevent their progression and the development of complications can be implemented by questioning students in different educational institutions.
\end{abstract}

Keywords

CVD; varicose veins; students; questionnaire; survey

Ivano-Frankivsk National Medical University, Ivano-Frankivsk, Ukraine

*Corresponding author: shepitvitru@gmail.com 
Problem statement and analysis of the latest research

Chronic venous disorders (CVD) are the most common diseases of peripheral vessels [1].They include phlebopathy ( $\mathrm{COs}$ clinical classaccording to the CEAP classification), telangiectasia, reticular (spider) veins (both of $\mathrm{C} 1$ clinical class) and disorders that are characterized by lower extremity varicose veins (VV) with potential edema formation and various trophic skin changes (C2-C6 clinical classes), namely primary VV (Ep etiological class), postthrombotic syndrome (Es etiological class) and angiodysplasia (Ec etiological class). The prevalence of thesediseases amongthe European and American adult population is $16-29 \%[2,3,4,5,6,7,8$, 9]. Etiology, diagnosisandtreatment ofCVDin the adult population are currently well covered in literature; however, their coursein children, adolescents and young people is still poorly understood [10]. These categories of the population rarely consult their physicians in case of initial manifestations of CVD.According to the National Epidemiological Survey DETECT, more than $75 \%$ of patient svisit surgeons in later stages (edema andtrophic skin changes) [11]. Therefore, earlydiagnosis and treatment of CVD are extremely important as it allows physicians to timely stop the progresion of the disease, as well as to provide anopportunity for young people to lead an active lifestyle and prevent disability.

The Objective of the Research was to increase the frequency of detecting CVD in young people by surveing the students using a specially designed questionnaire with an analysis of its results for timely treatment.

\section{Materials and Methods}

To detect lower extremity CVD, 1,007 students of the Ivano-Frankivsk National Medical University (IFNMU) were interviewed in January and February 2018. The distribution of the students by faculties and courses of study is shown in Table 1.

There were 737 (73.2\%) female students and $270(26.8 \%)$ male students. The students' age varied from 16 to 32 years. The median age was 19
Table 1. Distribution of the students by faculties and courses of study.

\begin{tabular}{cccc}
\hline $\begin{array}{c}\text { Years of } \\
\text { study }\end{array}$ & $\begin{array}{c}\text { Medical } \\
\text { Faculty }\end{array}$ & $\begin{array}{c}\text { Faculty of } \\
\text { Dentistry }\end{array}$ & $\begin{array}{c}\text { Medical } \\
\text { College }\end{array}$ \\
\hline I & 207 & 40 & - \\
II & 108 & - & - \\
III & 174 & 31 & 77 \\
IV & 156 & 3 & 43 \\
V & 137 & 6 & - \\
VI & 25 & - & - \\
\hline Total & 807 & 80 & 120 \\
\hline
\end{tabular}

(interquartile range, 18 to 21) years.

For the survey of the students, there was used a specially designed questionnaire including the following items:

- presence or absence of 11 most common symptoms of lower extremity CVD according to the international VEIN-TERM consensus document [12];

- in case of venous symptoms, how they affect the daily activity; in the presence of edema the degree of swelling spread (2 items of the Venous Clinical Severity Score (VCSS) [13];

- risk factors: the presence of lower extremity $\mathrm{VV}$ in parents, previous childbirth, frequent or rare use of high heels (over $5 \mathrm{~cm}$ );

- the presence or absence of objective symptoms of lower extremity CVD such as telangiectasia, reticular (spider) veins, lower extremity VV and leg swelling, C1-C3 clinical classes according to the CEAP classification [14];

- 20 items of the Chronic Venous Insufficiency Quality of Life Questionnaire 20 (CIVIQ-20) [15].

Special attention was paid to the fact that the respondents could clearly describe visual changes in their lower extremity veins. For this purpose, some photos of teleangiectasia, reticular veins and VV were included in the questionnaire. Based on the students' answers about the presence of such changes in the superficial veins, as well as venous complaints, the CEAP clinical class was 
determined.

According to the results of the students' answers to the CIVIQ-20 questionnaire, there were assessed changes in their quality of life (QoL) in case of VV with the calculation of both the Global Index Score, as well as the particular indices of its dimensions pain, physical, social and psychological ones. Each index was expressed as a percentage $(\%)$ ranging from $0 \%$ (minimum impact) to $100 \%$ (maximum impact).

The severity of venous symptoms and edema in the students with or without lower extremity VV was assessed according to the students' responses to two aforementioned questions of the VCSS. The absence of venous symptoms was assessed as 0 points; the recurrent presence of at least one symptom without affecting daily activities was assessed as 1 point; the presence of at least one symptom without affecting daily activities was assessed as 2 points; the presence of one or more symptoms with a significant impact on daily activities was assessed as 3 points. The absence of swelling was assessed as 0 points; the spread of swelling to the ankle was assessed as 1 point; the spread of swelling to the knee was assessed as 2 points; swelling over the knee was assessed as 3 points.

For statistical processing of information, a database was made in Microsoft Office Excel 2013 (Microsoft, USA) installed using the Office 365 University subscription, the Statistica 10 software (StatSoft, USA) and R (Revolution Analytics, USA) [16]. The frequency of qualitative data was presented as absolute (n) and relative (\%) frequencies with an indication of the exact $95 \%$ confidence interval $(\mathrm{CI})$ in the form of $\mathrm{n}(\% ; 95 \% \mathrm{CI})$. In the analysis of quantitative indicators, the nature of their value distribution was determined using the Shapiro-Wilk test. Since the distributions of all the indicators we studied turned out to be abnormal, their results were presented as "median (the $25^{\text {th }}$ and $75^{\text {th }}$ percentiles)". Qualitative indicators in two independent groups were compared using the Fisher's exact test, while quantitative indicators were compared using the Mann-Whitney U test. In addition, to assess the significance of certain symptoms and risk factors, their odds ratio was calculated according to generally recognized methods. The CI of the odds ratio was calculated as well. When testing statistical hypotheses, the p-value of 0.05 was considered statistically significant.

\section{Results}

Among 1,007 students, only 286 (28.1\%, 95 CI 25.3 - $31.0 \%$ ) individuals did not have any complaints and symptoms of CVD.

The majority of the respondents - 617 (61.3\%; 95 CI, 58.2 - 64.3\%) students - had no changes in their lower extremity veins; however, at least one venous symptom was present. Therefore, it can be argued that they developed phlebopathy of varying degrees.

Sixty-three $(6.3 \%, 95$ CI $4.8-7.9 \%)$ students reported lower extremity telangiectasias without reticular veins and VV; 11 (1.1\%; 95 CI 0.5 - 1.9\%) students reported reticular veins without lower extremity VV.

The most common complaints of all the respondents with certain venous complaints or changes in lower extremity veins without $\mathrm{VV}$ were leg fatigue $(48.5 \%)$, leg heaviness $(17.1 \%)$ and leg pain (12.2\%) (Fig. 1). The frequency of other complaints did not exceed $10 \%$. All the symptoms specific to CVD were found in the interviewed students.

Lower extremity VV were detected in 33 (3.3\%; 95 CI 2.3 - 4.6\%) cases. Among them, there were $14(1.4 \%, 95$ CI $0.8-2.3 \%)$ cases of leg swelling.

The distribution of the students according to the CEAP classification is shown in Table 2.

Among 31 students with symptoms of lower extremity VV (C2s and C3s clinical classes), the full spectrum of symptoms typical for CVD was not observed. No respondent complained of tingling feet and burning skin sensation in the lower extremities. All other symptoms occurred more often in the students with lower extremity VV as compared to the students without such disorder (Fig. 1).

The most common symptoms in the students with lower extremity VV were leg fatigue $(56.2 \%$; 95 CI 37.7 - 73.6\%) and leg heaviness (28.1\%; 95 CI $13.7-46.7 \%$ ). However, as we have already mentioned, these symptoms were most often observed 


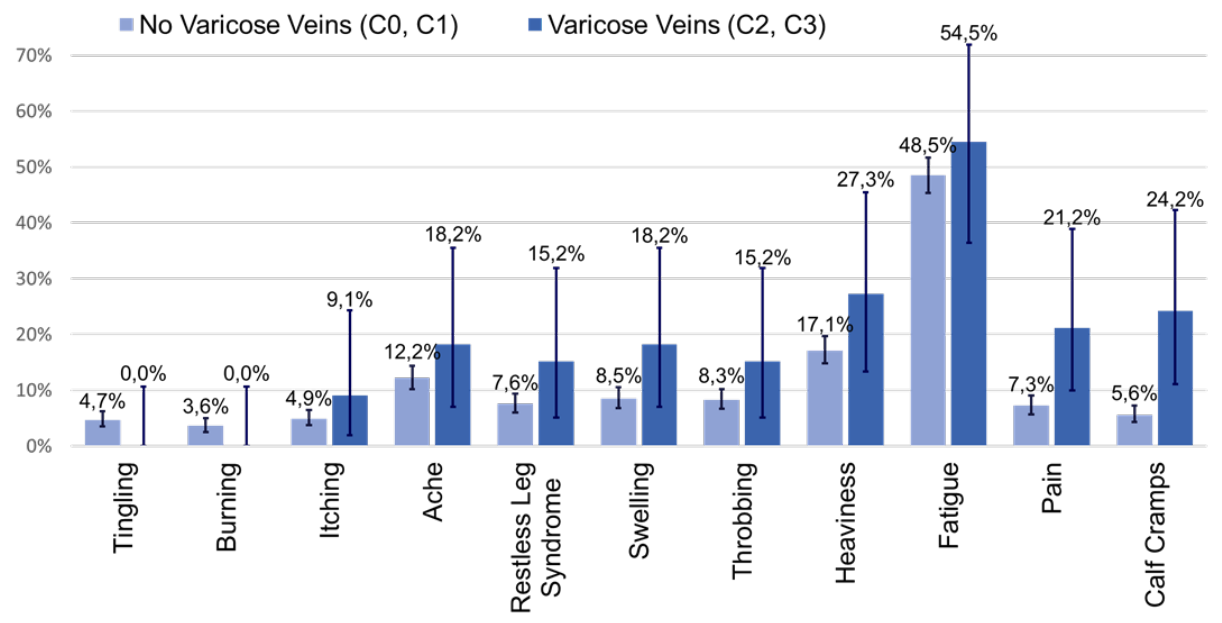

Figure 1. Comparison of symptoms in the absence and presence of lower extremity VV.

in the students without VV as well. Considering this fact, it was interesting to determine if there were symptoms that were more common among the students with VV than among those with phlebopathy, telangiectasia and reticular VV. Among the complaints we studied, only two symptoms, namely calf cramps $(\mathrm{p}=0.01)$ and leg pain $(\mathrm{p}=0.04)$ turned out to occur significantly more frequent in the students with VV. Thus, it can be considered that the appearance of these symptoms in young people is an important indication for an examination of the lower extremities for pathological venous refluxes, which are the cause of VV. To confirm this thesis for each of the studied symptoms, we calculated the odds ratio in the students with lower extremity VV.

According to the results, the studied indicator was the highest for symptoms such as leg pain and calf cramps (Fig. 2). Moreover, only for these two symptoms, the CI for the odds ratio did not include the value 1 . Therefore, the importance of these two symptoms for early diagnosis of VV was reaffirmed.

The impact of lower extremity VV on students' QoL is demonstrated in Table 3.

The students with lower extremity VV had statistically significant decrease in QoL which manifested itself as significantly higher Global Index Score of the CIVIQ-20. The analysis of the Global Index Score for each dimension showed a signifi- cant impact of lower extremity VV on the physical, psychological and pain components of QoL. Only social dimension was found not to be statistically significant affected by lower extremity VV.

The majority of students - 645 (64.1\%; 95\% CI $61-67 \%$ ) - could not indicate if their parents had VV. Therefore, an assessment of the impact of the presence of the disease in students' parents on the risk of VV development in the respondents was made based on the responses of 362 students who clearly indicated the presence or absence of lower extremity VV in their fathers and/or mothers. Among the respondents with lower extremity VV, only $36.4 \%$ (95\% CI $20.4-76.1 \%$ ) of the students did not know about the presence or absence of lower extremity VV in their parents, while among the respondents without lower extremity $\mathrm{VV}$, there were $65.0 \%$ (95\% CI $61.9-68.0 \%$ ) of students who did not know about the presence or absence of lower extremity VV in their parents. These results showed, that students are not often interested in the state of the lower limbs in their parents, especially if they do not have lower extremity VV. Among all the parents whose children were aware of the state of lower extremity veins in their families, $95.4 \%$ (95\% CI 92.6 - 97, 3\%) of the students had lower extremity VV. Since this figure was significantly higher than the frequency rate of lower extremity VV among the population, in our opinion, most 
Table 2. Distribution of the students according to the CEAP classification.

\begin{tabular}{|c|c|c|}
\hline $\begin{array}{c}\text { CEAP } \\
\text { clinical class }\end{array}$ & Characteristics & $\begin{array}{l}\text { Number of students, } \\
\text { n }(\% ; 95 \% \mathrm{CI})\end{array}$ \\
\hline $\mathrm{C}_{\mathrm{A}}$ & $\begin{array}{l}\text { No complaints; visible changes in lower } \\
\text { extremity veins }\end{array}$ & $\begin{array}{c}283 \\
(28.1 \% ; 95 \text { CI } 25.3-31.0 \%)\end{array}$ \\
\hline $\mathrm{CO}_{\mathrm{S}}$ & $\begin{array}{l}\text { No visible changes in lower extremity veins; } \\
\text { certain complaints }\end{array}$ & $\begin{array}{c}617 \\
(61.3 \% ; 95 \text { CI } 58.2-64.3 \%)\end{array}$ \\
\hline $\mathrm{C} 1_{\mathrm{A}}$ & Telangiectasias and/or reticular veins; no complaints & $\begin{array}{c}8 \\
(0.8 \% ; 95 \% \text { CI } 0.3-1.6 \%)\end{array}$ \\
\hline $\mathrm{C}_{\mathrm{S}}$ & $\begin{array}{l}\text { Telangiectasias and/or reticular veins; certain } \\
\text { complaints }\end{array}$ & $\begin{array}{c}66 \\
(6.6 \% ; 95 \% \text { CI } 5.1-8.3 \%)\end{array}$ \\
\hline $\mathrm{C} 2 \mathrm{~A}$ & VV; no complaints & $\begin{array}{c}2 \\
(0.2 \% ; 95 \% \text { CI } 0.0-0.7 \%)\end{array}$ \\
\hline $\mathrm{C} 2 \mathrm{~S}$ & VV; certain symptoms & $\begin{array}{c}17 \\
(1.7 \% ; 95 \% \text { CI } 1.0-2.7 \%)\end{array}$ \\
\hline $\mathrm{C} 3 \mathrm{~S}$ & Swelling associated with VV & $\begin{array}{c}14 \\
(1.4 \% ; 95 \% \text { CI } 0.8-2.3 \%)\end{array}$ \\
\hline
\end{tabular}

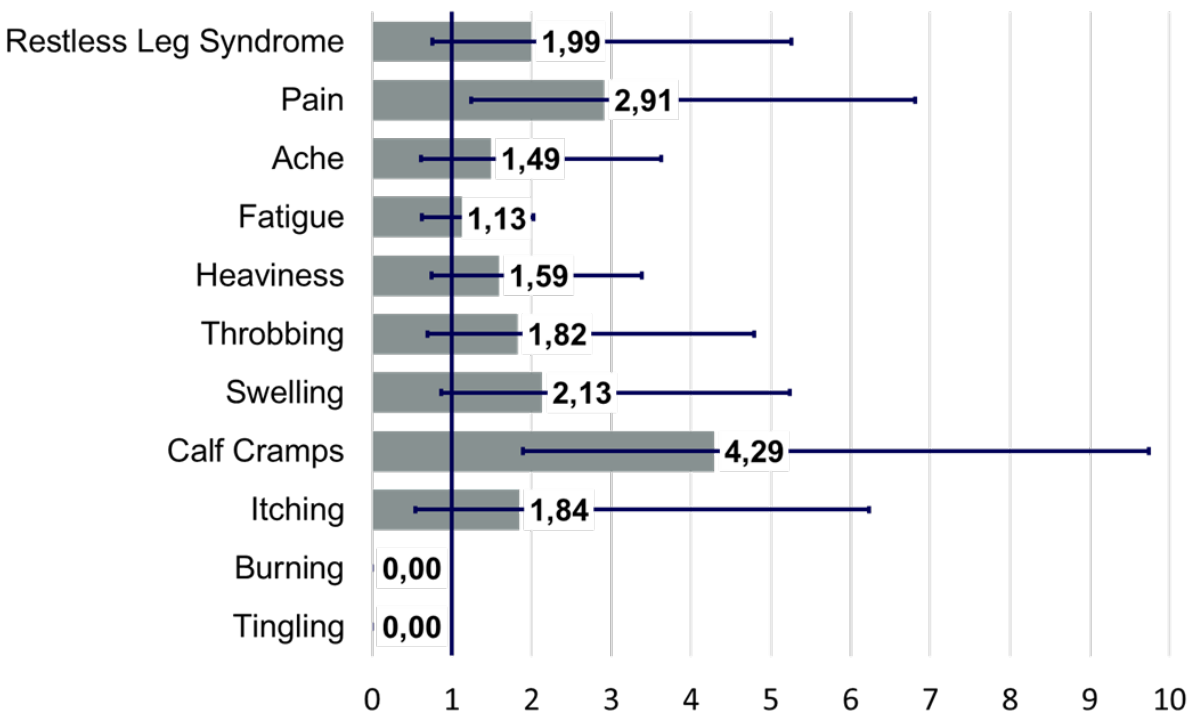

Figure 2. Odds ratio of detecting various subjective symptoms in the students with VV.

students got to know about the presence of lower extremity VV in their parents only when they saw them accidentally, and when the students did not remember this fact, they could not say for sure if their parents developed lower extremity VV.

Considering the aforementioned data, we could not compare the incidence rate of lower extremity VV among parents of the students with and without lower extremity VV, since both figures would approach $100 \%$ being not significantly different from each other. However, we could study the incidence rate of lower extremity VV in the students whose father, mother, both parents, or none of them had lower extremity VV as the aforementioned factors did not affect these calculations. Among the students, who were aware of the state of lower extremity veins in their families, lower extremity VV were more often indicated in mothers $-72.7 \%$ (95\% 
Table 3. Comparison of QoL in the students with VV and those without VV.

\begin{tabular}{|c|c|c|c|c|c|}
\hline \multirow[t]{2}{*}{ Dimensions } & \multicolumn{2}{|c|}{$\mathrm{VV}(\mathrm{C} 2, \mathrm{C} 3)$} & \multicolumn{2}{|c|}{ No VV $(\mathrm{C} 0, \mathrm{C} 1)$} & \multirow{2}{*}{$\begin{array}{c}\text { Statistical } \\
\text { significance } \\
\text { (p) }\end{array}$} \\
\hline & $\begin{array}{c}\text { Median value } \\
(\%)\end{array}$ & $\begin{array}{c}\text { Interquartile } \\
\text { range }(\%)\end{array}$ & $\begin{array}{c}\text { Median value } \\
(\%)\end{array}$ & $\begin{array}{c}\text { Interquartile } \\
\text { range }(\%)\end{array}$ & \\
\hline Physical & 6.3 & $0.0-12.5$ & 0.0 & $0.0-12.5$ & 0.004 \\
\hline Psychological & 8.3 & $4.2-15.3$ & 5.6 & $0.0-13.8$ & 0.03 \\
\hline Social & 8.3 & $0.0-16.7$ & 0.0 & $0.0-8.3$ & 0.051 \\
\hline Pain & 12.5 & $3.1-15.7$ & 0.0 & $0.0-6.1$ & 0.0002 \\
\hline Global Index Score & 8.8 & $2.5-15.0$ & 2.5 & $0.0-11.0$ & 0.005 \\
\hline
\end{tabular}

CI 66.6 - 76.1\%) - than fathers $-17.0 \%(95 \% \mathrm{CI}$ $14.4-22.6 \%)(\mathrm{p}=0.0006)$, that confirmed wellknown higher incidence of CVD in women. However, lower extremity VV were more often found in the students whose fathers suffered from lower extremity VV as compared to those whose mothers had lower extremity VV - 12.1\% (95\% CI 5.4 - $22.5 \%$ ) versus $4.2 \%$ (95\% CI 2.1 - 7.5\%), respectively $(\mathrm{p}=0.008)$. Among the students whose both parents suffered from lower extremity VV, this pathology was observed in one student only $(4.8 \%$, $95 \%$ CI $0.1-23.8 \%$ ), that was not significantly different from those who had one of parents with lower extremity VV. Similarly, only one student (6.2\%; 95\% CI, 0.2 - 30.2\%) whose parents had no lower extremity $\mathrm{VV}$, developed this disorder, that was not significantly different from the previous indicators.

Among females without lower extremity VV, $34.1 \%$ (95\% CI 29.7 - 38.3\%) of the respondents indicated wearing high heels (above $5 \mathrm{~cm}$ ) which was approximately 3 times more often as compared to female respondents with lower extremity $\mathrm{VV}$ $11.2 \%$ (95\% CI $0.0-21.7 \%)$ of women $(p=0.001)$.

Among 19 females with previous experience of childbirth, only one $(5.3 \%, 95 \%$ CI $0.1-26.0 \%)$ woman indicated the presence of lower extremity $\mathrm{VV}$. The proportion of female students with varicose veins among women who have never given birth was $3.1 \%$ (95\% CI 2.0 - 4.7), namely 22 out of 706 female students. This indicator was lower than in those who experienced childbirth; however, the difference between the indicators was not statistically significant $(\mathrm{p}>0.05)$.

The analysis of the students' answers to 2 ques- tions of the VCSS showed no significant difference between both the severity of symptoms related to the lower extremities and the presence or absence of VV in the students ( $\mathrm{p}>0.05)$; between the spread of edema in the lower extremities and the presence or absence of VV $(\mathrm{p}>0.05)$.

\section{Discussion}

Our study showed that among the students of the IFNMU, lower extremity VV were observed in $3.3 \%$ (95 CI $2.3-4.6 \%$ ) of the respondents. The comparison of the results obtained with the results of other studies was rather difficult, since most research studies we have found observed the incidence rate of lower extremity $\mathrm{VV}$ in a general aged population. And only a few European studies known to us presented the distribution of the prevalence of lower extremity VV by age groups, which was close to our sample (from 16 to 32 years), including people from 18 to 30 years of age (in Italian research study - from 21 to 30 years of age) $[2,3,4,5,6,7,8,9]$. In these studies, among individuals of the aforementioned age, lower extremity VV were found in 10-16\% of people. Although the age of the respondents in our study ranged from 16 to 32 years, $98.6 \%$ of them were no more than 23 years old; the median age was 19 years, the interquartile range was 18-21 years. Therefore, in our opinion, the factor of lower median age caused lower incidence of lower extremity VV among students of the IFNMU (3.3\%) as compared to the aforementioned studies.

In the Edinburgh Vein Study [4, 17], that examined a randomized sample of 1,566 men and women 
at the age of 18-64 years, telangiectasia and reticular veins on the legs were found in 1, $355(84 \%)$ individuals. They were most often found on the posterior surface of the calf, in the popliteal fossa and the lower third of the posterior thigh. In spite of that, in our study, the incidence of telangiectasia and reticular veins was significantly lower - $10.9 \%$ (including those with co-existent lower extremity VV). In our opinion, such results were due to the following reasons: firstly, $98.6 \%$ of the students were no more than 23 years old (the median age was 19 years), that means, they were significantly younger than the patients in the Edinburgh Vein Study; secondly, the respondents could not observe telangiectasias in their legs, as they are most common located in the aforementioned areas that people usually do not pay attention to.

It was equally important to assess the prevalence of phlebopathy. In our work, $61.3 \%$ of the respondents indicated venous complaints without visual changes in lower extremity veins. All this suggests that lower extremity venous disorders develop at a young age and are present in most young people. However, in our opinion, a real incidence of phlebopathy among the students may be lower, as the symptoms could only simulate a venous nature since there are no pathognomonic symptoms related to the lower extremity venous system.

In literature, the frequency of complaints such as leg heaviness and pain, fatigue and swelling, calf cramps were most often studied if they got worse at night $[3,6,7,8,9]$. We have found no study where the frequency of venous symptoms was studied only in young people with lower extremity VV without studying it in all age categories simultaneously. Obviously, therefore, in most studies, the frequency of each symptom was higher as compared to our study, since it is clear that young people develop severe forms of CVD less often, and consequently, the frequency of venous complaints should be less (Table 4).

Not all of the aforementioned researches compared the frequency of venous symptoms in the participants with and without lower extremity VV. This issue was not studied in the studies carried out in Russia and Turkey $[3,8]$. The studies carried out in Poland, Italy, and a joint research of Belgium and Luxembourg showed that all of the aforementioned complaints occurred more frequently $(\mathrm{p}<0.05)$ in the presence of lower extremity VV than in their absence $[6,7,9]$ (Table 4). In our study, in the students with lower extremity VV, only two symptoms, such as leg pain and calf cramps, occurred significantly more often. This suggests that in young people for early detection of CVD, it is important to pay attention to these symptoms.

During the validation of the CIVIQ-20 questionnaire, 4,048 people of all age groups were surveyed and observed in 18 countries [15]. The median of General Index Score in the participants without lower extremity $\mathrm{VV}(\mathrm{C} 0, \mathrm{C} 1)$ and those with lower extremity VV (C2, C3) was $28.12 \%$ and $36.81 \%$, respectively. The difference between these indicators was significant $(\mathrm{p}<0.001)$. It is worth mentioning that the identical indicators of our study were $2.5 \%$ and $8.8 \%$, respectively ( $\mathrm{p}=0.006$ ). Thus, the impact of problems associated with lower extremity veins on QoL was lower in young people. Obviously, this was due to the fact that severe forms of CVD occur in young people more rare.

Hereditary predisposition to CVD development has been studied since the middle of the last century. Most studies collected the data on the presence of lower extremity VV in parents through a patient survey. Perhaps for this very reason, their results were ambiguous. In our opinion, several studies were of special value, as the genetic risk was assessed by a physical examination of the patients' parents. In one of these researches, the patients with both parents suffering from lower extremity VV developed such disorder in $90 \%$ of cases [18]. If lower extremity $\mathrm{VV}$ were observed in one parent, the risk of their development for children was $25 \%$ in males and $62 \%$ in females. And finally, such risk for people whose parents did not suffer from lower extremity VV was $20 \%$ only. In our research, only participants whose fathers suffered from lower extremity VV, had a statistically significant risk of developing this pathology. A similar conclusion was made by K. Kroeger et al. [19]. They indicated that people whose fathers suffered from lower extremity VV had a significantly higher 
Table 4. Frequency of venous symptoms in the patients with lower extremity VV in various studies (\%).

\begin{tabular}{|c|c|c|c|c|c|c|}
\hline Symptoms & \multicolumn{6}{|c|}{ Frequency of symptoms, $(\%)$ and level of their significance } \\
\hline Researches, & $\begin{array}{c}\text { Our } \\
\text { study, }\end{array}$ & $\begin{array}{l}\text { Belgium } \\
\text { and } \\
\text { Luxembourg } \\
\text { [9], }\end{array}$ & $\begin{array}{l}\text { Italy } \\
\text { [7], }\end{array}$ & $\begin{array}{c}\text { Poland } \\
\text { [6], }\end{array}$ & $\begin{array}{c}\text { Russia } \\
\text { [3] }\end{array}$ & $\begin{array}{c}\text { Turkey } \\
\text { [8], }\end{array}$ \\
\hline n with lower extremity VV/ & $33 /$ & $1,556 /$ & $1,069 /$ & $13,753 /$ & $703 /$ & $171 /$ \\
\hline n without lower extremity VV & 974 & 4,453 & 4,118 & 2,6342 & 1,721 & 61 \\
\hline Leg pain & $21.2 *$ & $54.0 *$ & $53.0^{*}$ & $81.2^{*}$ & $14.8^{?}$ & $40.9^{?}$ \\
\hline Heaviness & 27.3 & $70.4^{*}$ & $75.5 *$ & $78.9 *$ & $36.3^{?}$ & $25.6^{?}$ \\
\hline Fatigue & 54.5 & - & $77.5^{*}$ & - & $32.8^{?}$ & $56.3^{?}$ \\
\hline Swelling & 18.2 & $52.7 *$ & $53.9 *$ & $61.1 *$ & $29.1^{?}$ & $25.7^{?}$ \\
\hline Calf cramps & $24.2 *$ & $46.5^{*}$ & - & $63.0^{*}$ & $14.6^{?}$ & - \\
\hline
\end{tabular}

Notes:

* - the difference of symptom frequency in the patients with and without lower extremity VV is statistically significant $(\mathrm{p}<0.05)$;

? - there was no information on the statistical significance in the source.

risk of disease development as compared to those whose mothers suffered from such disorder $-3.7 \%$ (95\% CI 3-4.6\%) versus $2.8 \%$ (95\% CI 2.4-3.3\%) $(\mathrm{p}<0.05)$.

The study of the effect of wearing high-heeled shoes for the development of lower extremity VV in women showed the opposite results. J. PotérioFilho et al. conducted an experiment, in which 10 healthy women participated. Each woman walked on a treadmill barefooted and wearing $7 \mathrm{~cm}$ highheeled shoes [20]. The hydrostatic venous pressure was measured on both shins at the beginning and at the end of the experiment. It was found that the final hydrostatic venous pressure was lower after walking without shoes than that after wearing highheeled shoes (53.6 and $63.1 \mathrm{~mm} \mathrm{Hg}$, respectively). According to the authors, the use of high-heeled shoes increases muscular effort during walking and diminishes the leg venous pressure as compared with barefooted.

A similar experiment was conducted by W. Tedesch Filho et al. [21]. However, in contrast to the aforementioned study, they made air plethysmography of the lower extremities and measured the indicators, such as the venous filling index (VFI), ejection fraction (EF), and residual volume fraction (RVF).
According to the authors, wearing of high heels reduced muscle pump function, as it reduced EF and increased RVF values. The frequent wearing of such shoes could cause venous hypertension and lead to lower extremity VV development.

Our findings, that female students with lower extremity VV are three times less likely to wear heels higher than $5 \mathrm{~cm}$ than those without lower extremity VV did not deny the results of the aforementioned studies. On the one hand, they could indicate a positive effect of such heels on the venous system of the lower extremities. However, in our view, females with lower extremity $\mathrm{VV}$ are less likely to wear such heels, as they know about their negative effect on the lower extremity venous system. In order to verify which of the aforementioned statements is correct, the questions in the questionnaire should be formed in a different way. For instance, "How often have you worn heels above $5 \mathrm{~cm}$ before the first symptoms occurred? (in case of the absence pf such symptoms - How often do you wear high heels?")

In current scientific literature, the association between childbirth and lower extremity VV is beyond doubt. In 2002, a survey of 3, 590 women in Tampere (Finnland) showed a direct correlation 
between the number of births females gave and the incidence of VV. During a first, second, third and fourth pregnancy, the probability of detecting VV was $38 \%, 43 \%, 48 \%$ and $59 \%$ more as compared to women who have never given birth [22]. However, there was no clear correlation between childbirth and the diseases in female students of the IFNMU, as there were only few women who gave birth, that did not allow us to adequately assess the effect of the aforementioned risk factor.

The analysis of our research results indicates the following: on the one hand, the data obtained through questionnaires depends on the subjective perception of symptoms of possible disease by a respondent. Surely, a more accurate assessment of disease prevalence requires direct examination of research participants. On the other hand, a questionnaire is the easiest and most affordable way to assess the trend in the prevalence of the disease, its symptoms and risk factors among schoolchildren, college and university students, employees of individual private enterprises and government agencies. The use of such a survey can be of great value for the rapid detection of young people with CVD for their timely and adequate treatment.

\section{Conclusions}

1. The spectrum of CVD among the students of the IFNMU included: lower extremity VV $3.3 \%$ (95\% CI $2.3-4.6 \%)$, reticular veins without VV - 1.1\% (95 CI 0.5\% - 1.9\%), telangiectasias without $\mathrm{VV}$ and reticular veins - 6.3\% (95\% CI 4.8 - 7.9\%), phlebopathies $61.3 \%$ (95\% CI 58.2 - 64.3\%)

2. Leg pain and calf cramps can be considered as the most important subjective symptoms for early diagnosis of lower extremity $\mathrm{VV}$ in young people.

3. The presence of lower extremity VV in a father results in higher risk of detecting this pathology in the respondent than the presence of lower extremity VV in a mother: $12.1 \%$ (95\% CI 5.4-22.5\%) versus $4.2 \%$ (95\% CI $2.1-7.5 \%)(\mathrm{p}=0.008)$.

4. Early diagnostics of lower extremity VV in young people with the aim of further adequate treatment to prevent their progression and the development of complications can be implemented by questioning students in different educational institutions.

\section{References}

[1] Whiteley MS. Understanding venous reflux the cause of varicose veins and venous leg ulcers. Whiteley Publishing Ltd. c2011. 98p.

[2] Clark A, Harvey I, Fowkes FG. Epidemiology and risk factors for varicose veins among older people: cross-sectional population study in the UK. Phlebology. 2010;25(5):236240. DOI: https://doi.org/10.1258/ phleb.2009.009045 [PMid:20870870]

[3] Zolotukhin IA, Seliverstov EI, Shevtsov YN et al. Prevalence and risk factors for chronic venous disease in the general Russian population. Eur J Vasc Endovasc Surg. 2017;54(6):752758. DOI: https://doi.org/10.1016/ j.ejvs.2017.08.033 [PMid:29031868]

[4] Ruckley CV, Evans CJ, Allan PL et al. Chronic venous insufficiency: clinical and duplex correlations. The Edinburgh Vein Study of venous disorders in the general population. J Vasc Surg. 2002;36(3):520525. DOI: https://doi.org/10.1067/ mva.2002.126547 [PMid:12218976]

[5] Criqui $\mathrm{MH}$, Denenberg JO, Bergan $\mathrm{J}$ et al. Risk factors for chronic venous disease: the San Diego Population Study. J Vasc Surg. 2007;46(2):331-337. DOI: https://doi . org/10.1016/j.jvs.2007.03.052 [PMid:17600666 PMCid:PMC2023874]

[6] Jawien A, Grzela T, Ochwat A. Prevalence of chronic venous insufficiency in men and women in Poland: multicentre crosssectional study in 40,095 patients. Phlebology. 2003;18(3):110-122. DOI: https://doi. org/10.1258/026835503322381315 
[7] Chiesa R, Marone EM. Limoni C et al. Chronic venous insufficiency in Italy: the 24-cities cohort study. Eur J Vasc Endovasc Surg. 2005;30(4):422-429. DOI: https://doi . org/10.1016/j.ejvs.2005.06.005 [PMid:16009576]

[8] Diken AI, Yalçınkaya A, Aksoy E et al. Prevalence, presentation and occupational risk factors of chronic venous disease in nurses. Phlebology. 2016;31(2):111117. DOI: https://doi .org/10.1177/ 0268355514567491 [PMid:25577573]

[9] Vuylsteke ME, Thomis S, Guillaume G et al. Epidemiological study on chronic venous disease in Belgium and Luxembourg: prevalence, risk factors, and symptomatology. Eur J Vasc Endovasc Surg. 2015;49(4):432439. DOI: https://doi.org/10.1016/ j.ejvs.2014.12.031 [PMid:25701071]

[10] Studennikova VV, Severgina LO, Dzyundzya AN, Korovin IA. Lower extremity varicose veins in childhood and at a young age: Mechanism of development and specific features. Archive of Pathology. 2017;79(4):56-60. DOI: https://doi.org/10.17116/ patol201779456-60 [PMid:28792000]

[11] Chernukha LM, Guch AA, Todosyev AV. Khronicheskaya venoznaya nedostatochnost nizhnikh konechnostey ili tyazhelyye formy khronicheskikh zabolevaniy ven. Strategiya lecheniya. Klinicheskaya flebologiya. 2012;5(1):84-88.

[12] Eklof B, Perrin M, Delis KT et al. Updated terminology of chronic venous disorders: the VEIN-TERM transatlantic interdisciplinary consensus document. J Vasc Surg. 2009;49(2):498-501. DOI: https://doi. org/10.1016/j.jvs.2008.09.014 [PMid:19216970]

[13] Launois R, Reboul-Marty J, Henry B. Construction et validation d'un indicateur spécifique de qualité de vie: le cas de l'insuffisance veineuse chronique des membres inférieurs. J Econ Med. 1994;12:109-126.

[14] Eklöf B, Rutherford RB, Bergan JJ et al. Revision of the CEAP classification for chronic venous disorders: consensus statement. J Vasc Surg. 2004;40(6):1248-1252. DOI: https://doi.org/10.1016/j.jvs. 2004.09 .027 [PMid:15622385]

[15] Launois R, Mansilha A, Jantet G. International psychometric validation of the Chronic Venous Disease quality of life Questionnaire (CIVIQ-20). Eur J Vasc Endovasc Surg. 2010;40(6):783-789. DOI: https://doi. org/10.1016/j.ejvs.2010.03.034 [PMid:20920862]

[16] R Development Core Team (2011). R: A language and environment for statistical computing. R Foundation for Statistical Computing, Vienna, Austria. Available from: http://www.Rproject.org/

[17] Ruckley CV, Evans CJ, Allan PL et al. Telangiectasia in the Edinburgh Vein Study: epidemiology and association with trunk varices and symptoms. Eur $J$ Vasc Endovasc Surg. 2008;36(6):719-274. DOI: https://doi.org/10.1016/j.ejvs. 2008.08 .012 [PMid:18848475]

[18] Cornu-Thenard A, Boivin P, Baud JM et al. Importance of the familial factor in varicose disease. Clinical study of 134 families. J Dermatol Surg Oncol. 1994;20(5):318-326. DOI: https://doi.org/10.1111/ j.1524-4725.1994.tb01631.x

[PMid:8176043]

[19] Kroeger K, Ose C, Rudofsky G et al. Risk factors for varicose veins. Int Angiol. 2004;23(1):29-34.

[20] Potério-Filho J, Silveira SA, Potério GM et al. The effect of walking with high-heeled shoes on the leg venous pressure. Angiology. 2006;57(4):424-430. DOI: https://doi. 
org/10.1177/0003319706290744

[PMid:17022377]

[21] Tedeschi WF, Dezzotti NR, Joviliano EE et al. Influence of high-heeled shoes on venous function in young women. J Vasc Surg. 2012;56(4):1039-1044. DOI: https : / / doi . org/10.1016/j.jvs.2012.01.039

[PMid:22483354]

[22] Laurikka JO, Sisto T, Tarkka MR et al. Risk indicators for varicose veins in fortyto sixty-year-olds in the Tampere varicose vein study. World J Surg. 2002;26(6):648651. DOI: https: / /doi.org/10.1007/ s00268-001-0283-1 [PMid:12053212]
Received: $2019-06-17$

Revised: 2019-09-20

Accepted: 2019-09-22 